University of South Carolina

Scholar Commons

4-2014

\title{
Large-Scale Site and Frequency Diversity in Urban Peer-to-Peer Channels for Six Public Safety Frequency Bands
}

\author{
David W. Matolak \\ University of South Carolina - Columbia, matolak@cec.sc.edu \\ Kate A. Remley \\ Christopher L. Holloway \\ Qian Zhang \\ Qiong Wu
}

Follow this and additional works at: https://scholarcommons.sc.edu/elct_facpub

Part of the Signal Processing Commons, and the Systems and Communications Commons

\author{
Publication Info \\ Postprint version. Published in IEEE Transactions on Wireless Communications, Volume 13, Issue 4, 2014, \\ pages 2025-2033. \\ (C) IEEE Transactions on Wireless Communications, 2014, IEEE \\ Matolak, D., Holloway, C., Remley, K., Zhang, Q., Wu, Q. (2014). Large-Scale Site and Frequency Diversity in \\ Urban Peer-to-Peer Channels for Six Public Safety Frequency Bands, IEEE Transactions on Wireless \\ Communications, 13(4), 2025-2033. \\ http://dx.doi.org/10.1109/TWC.2014.022614.130816
}

This Article is brought to you by the Electrical Engineering, Department of at Scholar Commons. It has been accepted for inclusion in Faculty Publications by an authorized administrator of Scholar Commons. For more information, please contact digres@mailbox.sc.edu. 


\title{
Large-Scale Site and Frequency Diversity in Urban Peer-to-Peer Channels for Six Public-Safety Frequency Bands
}

\author{
David W. Matolak, Senior Member, IEEE, Kate A. Remley, Fellow, IEEE, \\ Christopher L. Holloway, Fellow, IEEE, Qian Zhang, Member, IEEE, and Qiong Wu
}

\begin{abstract}
We report on peer-to-peer large-scale wireless channel characteristics for an urban environment in six public-safety bands, for five simultaneous receiving sites. Results are based upon measurements taken in Denver in July 2009 with stationary receivers and a pedestrian transmitter. The six frequencies at which we measured are (in MHz) 430, 750, 905, 1834, 2400, and 4860. We quantify both site and frequency diversity, and show that 5 -site selection yields minimum average gains of $15 \mathrm{~dB}$ in mean received power levels; 5 -site selection diversity also reduces received power variation by 17-29 $\mathrm{dB}$, depending on frequency. Frequency diversity yields similar gains. By approximating received powers as lognormal, we describe an analytical method to approximate the cdf of the per-site, or per-frequency (or both) maximum received power. These data and diversity models should be useful for public-safety and ad hoc communication system designers, and for cooperative diversity schemes, wherein multiple users act as a virtual array.
\end{abstract}

Index Terms-Channel characterization and modeling, propagation, public safety, wireless system.

\section{INTRODUCTION}

$\mathbf{P}$ UBLIC-SAFETY communications are seeing increased attention [1], [2]. Whether for natural or human-made emergencies, public-safety officials are acutely aware of the need for reliable communications for "emergency responders" during and after emergency events. Coverage is of primary importance to this community, which utilizes ad hoc networking and diversity schemes. This paper reports on largescale, narrowband path gains using both site and frequency diversity. These data were collected in an urban environment in a configuration relevant to the responder community. Data were collected at frequencies relevant to new public-safety spectrum allocations. These allocations include two $12 \mathrm{MHz}$ blocks in the $700 \mathrm{MHz}$ band (764-776 MHz and 794-806 $\mathrm{MHz}$ ), formerly allocated to television broadcast, and a 50 $\mathrm{MHz}$ band from 4940-4990 $\mathrm{MHz}$ that has also been recently allocated.

Manuscript received May 6, 2013; revised September 18 and December 12, 2013; accepted December 28, 2013. The associate editor coordinating the review of this paper and approving it for publication was A. Zajic.

This paper is partial work of the U.S. government, not subject to copyright in the United States.

D. Matolak is with the University of South Carolina, Department of Electrical Engineering, Columbia, SC, 29208 USA (e-mail: matolak@sc.edu).

K. Remley and C. Holloway are with the National Institute of Standards \& Technology, Dept. of Commerce, Electromagnetics Division, Boulder, CO, 80305 USA (e-mail: kate.remley@nist.gov).

Q. Zhang and Q. Wu are with Ohio University, School of Electrical Engineering \& Computer Science, Athens, OH 45701 USA).

Digital Object Identifier 10.1109/TWC.2014.022614.130816
In the past, public-safety communication systems have often used a "single cell" for "dispatch" purposes; in these systems, mobile users connect only to a single base station that must cover a wide area. For emergency responder events, new deployments, called the jurisdictional area network (JAN) and incident area network (IAN) are in the process of being deployed [1], [2]. A JAN can operate as a single- or a multi-cell system over a wide area (e.g., city-wide), whereas the IAN can operate as an ad hoc network that is temporarily configured to provide communication services for emergency responders during and after an emergency event. The IAN environments could include urban settings, outdoor-outdoor, outdoor-indoor, and indoor-indoor. In ad hoc cases, elevated base stations are not deployed; hence, communications will be ground-based, or "peer-to-peer" (P2P), with low-elevation antennas between mobile units and base(s). Specific candidates for public safety communication systems have also been recently addressed [3][5].

In general, ad hoc networks are also seeing much attention in the research community; references [6]-[22] represent a sampling of work on various aspects of these networks. Mobile ad hoc network (MANET) topics of study include routing [6] and capacity [7], connectivity [8], cross-layer design [9], [10], physical layer issues related to these topics [11], [12], and multiple access, duplexing, and multiplexing [13]-[16]. Few works in the area address the issue of inter-node propagation or diversity [20]-[22]. Our results on site diversity are also germane to cooperative diversity schemes, in which multiple users act as a virtual array [23]. While speculating on how to conduct the signal processing necessary for cooperative multipoint (CoMP) implementation is outside the scope of this work, the findings presented here could be used by designers of CoMP systems to develop methods for multiplebase-station selection and beamforming algorithms based on signal strength.

Also well known is that wireless channels have been characterized for a large number of environments and in multiple frequency bands, with cellular channels perhaps seeing the most attention; e.g., [24]-[27]. In addition, indoor channels have seen much attention [28], and newer, atypical channels such as vehicle-to-vehicle [29] have also been measured and modeled, whereas ground-based (or P2P) channels have seen far less attention. Ground-based urban path loss in ultra-highfrequency (UHF) bands was reported in [30]. Our recent work [31] also reports path loss models for a single urban 
street, and in addition, provides new detailed tapped delay line channel models based upon wideband measurements for the $700 \mathrm{MHz}$ and $4900 \mathrm{MHz}$ public-safety bands. Work on microcell channels, studied extensively by standards bodies, typically focuses on 3-4 $\mathrm{m}$ antenna heights, rather than the person-height $(1.6 \mathrm{~m})$ conditions reported here. With smaller antenna heights, line-of-sight links between transmitter and receiver will be less likely than in microcell and macrocellular cases, with the result that path gains will generally be smaller in the peer-to-peer case.

However, few references report on characteristics of simultaneous propagation to multiple sites, or on propagation of multiple frequencies that span a very wide frequency range [32], particularly for low antenna height conditions. Our work here does just this: we measured received power from a single mobile (pedestrian) transmitter to five receivers, simultaneously, in an urban environment. We did this for six continuous wave $(\mathrm{CW})$ frequencies in or very near to current publicsafety bands, spanning a decade in frequency: $430 \mathrm{MHz}, 750$ $\mathrm{MHz}, 905 \mathrm{MHz}, 1834 \mathrm{MHz}, 2400 \mathrm{MHz}$, and $4860 \mathrm{MHz}$. From these results, we compute statistics on site diversity and frequency diversity in the urban P2P environment. We also provide analytical cumulative distribution functions that can be used to approximate the diversity gains, providing an indication of improved coverage through the use of diversity. Work most closely related to ours may be that in [33]-[35]. In [34] and [35], only a single (tall) base station site was used for studying correlations across frequency, whereas in [33] multiple sites were used at a single frequency to study spatial correlation. Reference [34] used a frequency span slightly less than two and considered correlations of path loss and shadowing separately. Reference [35] provided results for a frequency span of approximately 2.25, and reported on correlations of shadowing and small-scale fading separately. Link distance in both these references are larger than ours (generally $>1 \mathrm{~km}$ ). The authors of [33] report results for $2.45 \mathrm{GHz}$ for both outdoor-to-indoor and indoor-to-indoor (I2I) path loss, shadowing, and small scale fading. The I2I results are peer-to-peer NLOS, and the authors cite inter-site shadowing correlations for this case: the "single-mobile" with "Tx"subsets are most closely related to our case, and for these subsets the mean shadowing correlations in [33] are small $(-0.01$ to 0.37$)$. In addition to the differences between [33] and our paper in terms of the indoor setting vs. our outdoor setting, the indoor link distances (maximum $\sim 25 \mathrm{~m}$ ) are much smaller than ours. Hence the results we present here can be considered a generalization of those in [33]-[35], with a larger frequency range, for our specific peer-to-peer setting.

Several projects in NIST's Public Safety Communications Research Laboratory have been funded by the Department of Justice's Community-Oriented Policing Services (COPS) program; these include work described in [31] and [36]-[40]. The site- and frequency-diversity results of this paper are a continuation of this work.

The remainder of this paper is organized as follows: Section II describes the urban environment and measurements. Section III presents a description of large-scale site diversity, and Section IV provides a condensed but analogous discussion of large-scale frequency diversity. Section V briefly describes

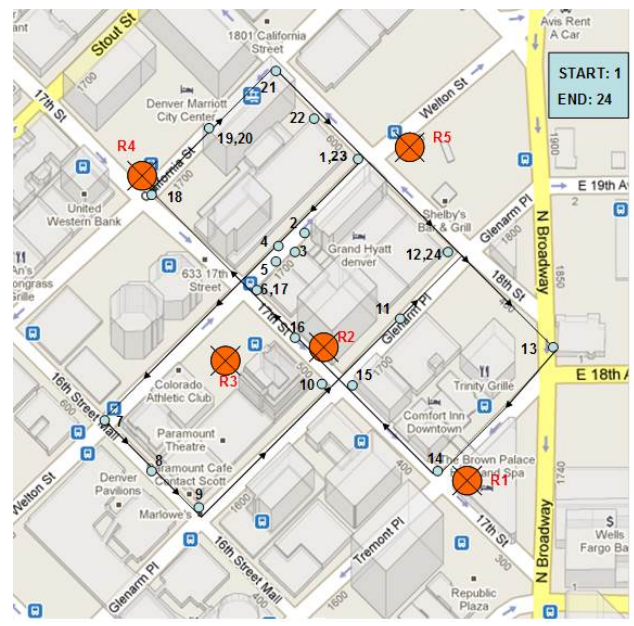

Fig. 1. Google map view of test area in downtown Denver. Transmit path indicated by line with arrows and numbered points from 1 to 24 , and receiver locations indicated by circles, with $i^{t h}$ receiver denoted $R_{i}$.

combined site and frequency diversity, and Section VI provides conclusions.

\section{Measurement Summary}

Our measurements were taken outdoors in the financial district of downtown Denver on Saturday, July 18, 2009. This area is the site of many large (over 20 story) buildings. Fig. 1 shows an illustration of the test area constructed from a Google map view ${ }^{1}$. The test area was bounded by California Street and Tremont Place (running approximately southwest to northeast), and by the $16^{\text {th }}$ Street Mall and $18^{\text {th }}$ Street (running approximately northwest to southeast). In Fig. 1, the numbers denote consecutive positions of the transmitter (1-24) and the circles denoted $R_{i}, i \in\{1,2,3,4,5\}$ indicate the fixed receiver locations. Choice of receiver site was constrained by the logistics of identifying sites having sufficient physical area for our instruments without blocking pedestrian traffic. Our goal was to use a realistic set of site locations. However, our receiver placement should be considered strictly as a representative network topology rather than a generalized use case.

For each test frequency, the two-person transmit team walked the numbered path at typical pedestrian velocities ( $\sim 5 \mathrm{~km} / \mathrm{hr}=1.4 \mathrm{~m} / \mathrm{s}$ ), stopping at corners (see Fig. 2). Distances were measured between all receivers and corner locations. During the transmitter walk, the receivers collected data continuously, sampling the power at a rate of approximately 2 samples/second. At the highest frequency of 4860 $\mathrm{MHz}$, samples are spaced by up to $11 \lambda$. This sampling rate is sufficient for assessing large-scale effects. We are not concerned with small-scale multipath fading and, in fact, we perform additional post processing to average this out. The transmitting units were $\mathrm{CW}$ transmitters [41] set to a power level of 1 watt for frequencies of $430 \mathrm{MHz}, 750 \mathrm{MHz}$, $905 \mathrm{MHz}, 1834 \mathrm{MHz}$, and 2 watts for frequencies of 2400 and $4860 \mathrm{MHz}$. The transmit antennas were quarter-wave

${ }^{1}$ (C) 2010 Google, Map Data (c)2010 Tele Atlas. Use of brand names does not imply endorsement by the U.S. government. Other brands may work as well or better. 


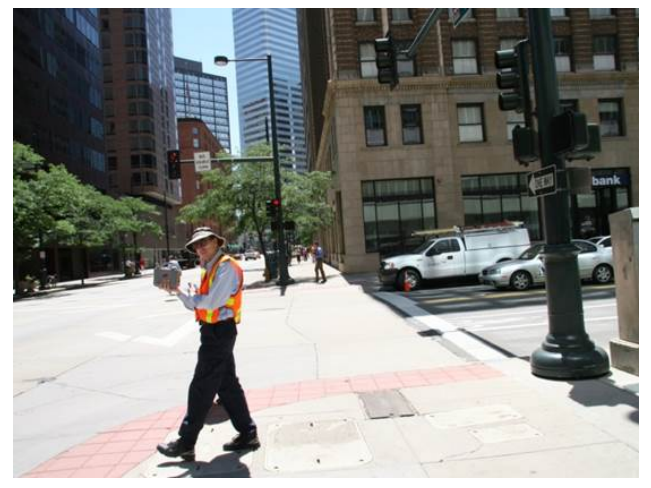

Fig. 2. Pedestrian transmit team at corner of $17^{\text {th }}$ and Welton Streets.

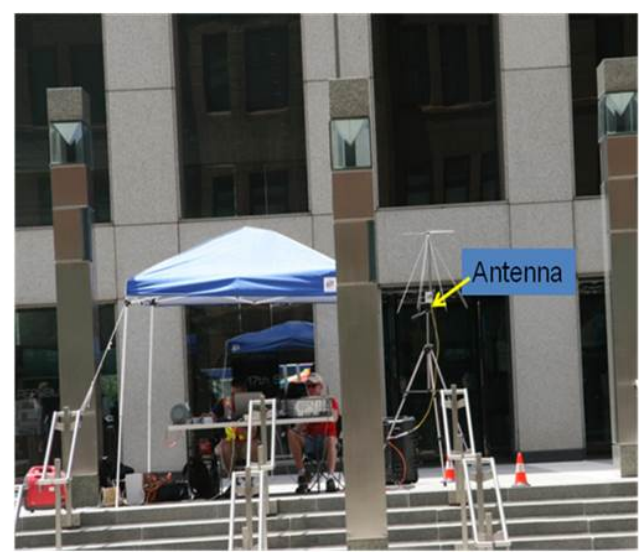

Fig. 3. Site 1 at $17^{\text {th }}$ St. and Tremont Pl.

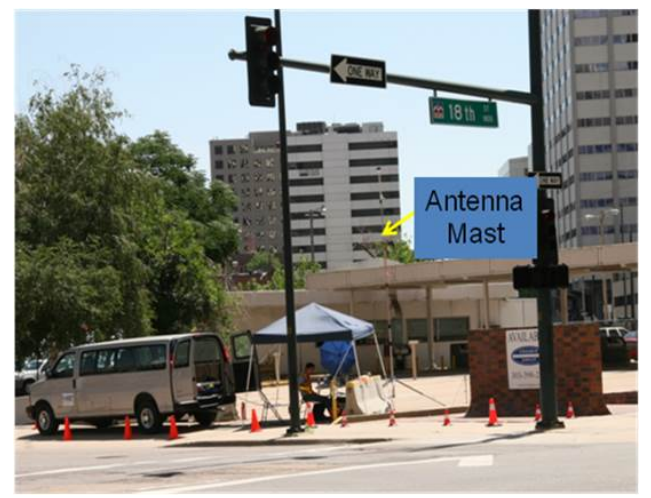

Fig. 4. Site 5 at $18^{\text {th }}$ and Welton Streets.

monopoles. The receivers were spectrum analyzers equipped with wideband (300 MHz to $1 \mathrm{GHz}$ ) omnidirectional discone antennas for the lower three frequencies, and wideband $(1 \mathrm{GHz}$ to $18 \mathrm{GHz}$ ) omnidirectional conical monopole antennas for the upper three frequencies. All antennas were omnidirectional in azimuth, with elevation beamwidths of around $30^{\circ}$ and gains of approximately $3 \mathrm{~dB}$ in azimuth over isotropic. Antenna heights were approximately $1.6 \mathrm{~m}$ for sites $1-4$ (see Fig. 3), replicating a peer-to-peer transmission scenario and approximately $5 \mathrm{~m}$ for site 5 (see Fig. 4), replicating a repeater- or tower-type transmission scenario). All antenna polarizations were vertical. The spectrum analyzers were connected to laptop computers to collect and archive the received power samples. The spectrum analyzer resolution bandwidth was set to $1 \mathrm{kHz}$, and the power accuracy is $\pm 1 \mathrm{~dB}$, as given by the manufacturer's specifications. (The $1 \mathrm{kHz}$ resolution bandwidth allowed for any small transmitter frequency drift. According to the manufacturer of the transmitter, frequency drift is on the order of a few tens of hertz at most, and is lower than that for the spectrum analyzer receiver.) The noise floor was approximately $-114 \mathrm{dBm}$ for the $4860 \mathrm{MHz}$ frequency $^{2}$, corresponding to a minimum recordable path gain of approximately $-145 \mathrm{~dB}$. Coordination between transmit and receive teams was maintained with walkie-talkies (at $\sim 162$ $\mathrm{MHz}$ - well out of band of the measurements, and only intermittently used), and link distances ranged from approximately a few meters to nearly $350 \mathrm{~m}$.

The path followed by the transmitter team yielded both lineof-sight (LOS) and non-LOS (NLOS) conditions. Each walk took approximately 30 minutes, and yielded approximately 4000 to 5000 power samples for each test frequency. Both pedestrian and vehicular traffic were moderate throughout the testing; the test period was from approximately 8:30 am to noon. Prior to testing at each frequency, we first ensured with our spectrum analyzers that no interfering signals were present. We also recorded a segment of noise samples only (with transmitters turned off) to allow collection of a noise reference. Although slow-moving traffic was present, causing small-scale fading variations, ultimately these smallscale fading effects are removed via post-processing on the narrowband samples; our characterizations are for large-scale effects only.

\section{Site Diversity}

With known transmit power, cable losses, and antenna gains, we were able to compute propagation path loss from the transmitter to each receiver site by measuring received power.

\section{A. Quantifying Diversity Improvements}

As noted previously, we measured received power at all five sites simultaneously. Fig. 5 shows a plot of power gain vs. time for all five sites for $4860 \mathrm{MHz}$. The gain values were smoothed with a moving-average filter of size approximately $20 \lambda$ to remove small-scale fading effects. In this figure, we have not separated out any data for LOS vs. NLOS regions-the gain values are simply those for each site over time, as would occur in an actual ad hoc setting. For sites 1 and 5, for example, the fraction of time in which LOS conditions existed was approximately 0.19 and 0.23 , respectively; the LOS fraction was below 0.1 for the remaining sites. In Fig. 5 , the range of gain variation is near $70 \mathrm{~dB}$ (or more) for the five sites, and we see clearly that low gains on all five sites do not simultaneously occur. This brings to light the idea of large scale site diversity, wherein, in an ad hoc network, if the multiple receiving sites are all connected to a single processing site, the multiple received signals can be used to improve the aggregate received signal level. This idea has long been explored in cellular, e.g., [42], wherein the dual case of site selection by the mobile unit was analyzed. Here we extend the idea to the ad hoc setting, and compare analytical

\footnotetext{
${ }^{2}$ For frequencies 430, 750, 905, 1834, and $2400 \mathrm{MHz}$, noise floors were approximately $-109,-103.5,-115,-115$, and $-114 \mathrm{dBm}$, respectively.
} 


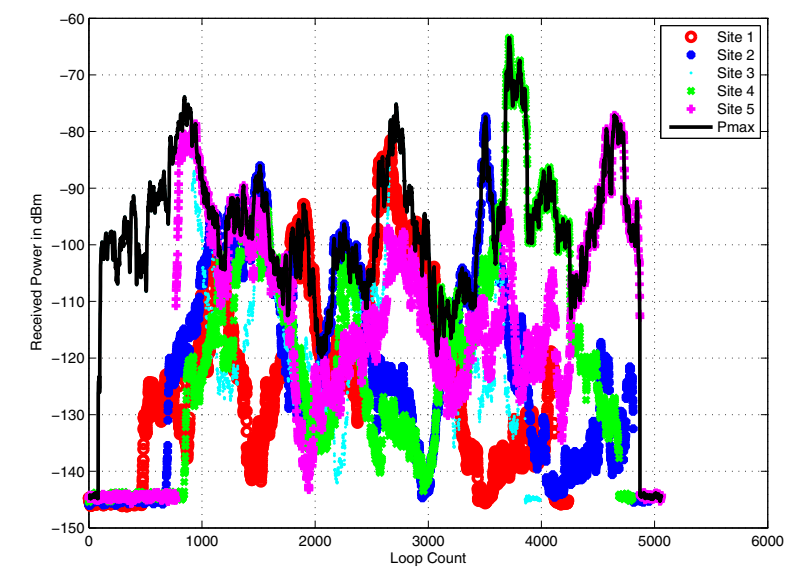

Fig. 5. Received power vs. time for five receiver sites, plus maximum power over all sites, $4860 \mathrm{MHz}$.

TABLE I

MINIMUM AND MAXIMUM REDUCTION IN PATH GAIN VARIATION VIA FIVE-SITE SELECTION DIVERSITY (DECIBELS).

\begin{tabular}{|c|c|c|}
\hline $\begin{array}{c}\text { Frequency } \\
(\mathrm{MHz})\end{array}$ & $\begin{array}{c}\text { Minimum } \\
\text { Variation Reduction }\end{array}$ & $\begin{array}{c}\text { Maximum } \\
\text { Variation Reduction }\end{array}$ \\
\hline 4860 & 0 & 17 \\
\hline 2400 & 8 & 25 \\
\hline 1834 & 10 & 28 \\
\hline 905 & 10 & 23 \\
\hline 750 & 10 & 18 \\
\hline 430 & 1 & 29 \\
\hline
\end{tabular}

and measured results for the practical condition of unequal statistics from each site. In Fig. 5, site selection diversity is applied, in which the curve labeled $P_{\max }\left(\Rightarrow G_{\max }\right)$ shows the maximum gain value for each sample. This maximum is selected from among the gain values of each of the five sites. In this case, the range of gain variation is reduced substantially from nearly $70 \mathrm{~dB}$ to approximately $50 \mathrm{~dB}$. Similar results are obtained for the other frequencies. Table I lists the minimum and maximum reductions in path gain variation (in decibels) when five-site selection diversity is employed. Referring to Fig. 5, these reductions are computed by comparing the variation of the $G_{\max }$ plot to the variation for the gain plots for each of the five individual sites. Note that other diversity mechanisms are also possible; e.g., equalgain combining (EGC) and maximal-ratio combining (MRC) [43]. Selection diversity is the simplest, as this does not require signal phase information and alignment. This simplicity comes at the expense of slightly reduced performance in comparison to EGC and MRC.

In addition to reductions in path gain variation, increases in mean path gain were likewise observed. Table II lists the minimum, average, and maximum increases in the mean path gain for each frequency obtained via the five-site selection: for each frequency, these statistics on increases in mean path gain are taken over all five sites. For clarity, let $G_{a}=\left[G_{a 1}, G_{a 2}, G_{a 3}, G_{a 4}, G_{a 5}\right]$ be the vector of five mean path gain values $(\mathrm{dB})$ for each of the five sites (this pertains to a given frequency, e.g., for $4860 \mathrm{MHz}$ in Fig. 5,
TABLE II

STATISTICS FOR INCREASES (DB, OVER ALL FIVE SITES) IN MEAN PATH GAIN VIA FIVE-SITE SELECTION DIVERSITY.

\begin{tabular}{|c|c|c|c|}
\hline Frequency $(\mathrm{MHz})$ & $\Gamma_{\min }$ & $\Gamma_{a v g}$ & $\Gamma_{\max }$ \\
\hline 4860 & 12.6 & 19.9 & 25.1 \\
\hline 2400 & 9.5 & 20.0 & 25.4 \\
\hline 1834 & 10.6 & 17.6 & 22.9 \\
\hline 905 & 14.0 & 18.8 & 23.4 \\
\hline 750 & 10.8 & 15.3 & 18.4 \\
\hline 430 & 16.2 & 19.1 & 21.8 \\
\hline
\end{tabular}

these are the means of the five individual site gain plots). Let $G_{m}$ denote the mean gain of the five-site maximum (e.g., the mean of the $G_{\max }$ curve in Fig. 5). Then the minimum increase is $\Gamma_{\min }=G_{m}-\max \left(G_{a}\right)$; maximum increase is $\Gamma_{\max }=G_{m}-\min \left(G_{a}\right)$, and average increase is $\Gamma_{a v g}=G_{m}-\operatorname{mean}\left(G_{a}\right)$. As an example, for $750 \mathrm{MHz}$, the minimum increase in mean path gain over all five sites is $\Gamma_{\min }=10.8 \mathrm{~dB}$; the average increase in mean path gain over the five sites is $\Gamma_{\text {avg }}=15.3 \mathrm{~dB}$, and the maximum increase in mean path gain over all five sites is $\Gamma_{\max }=18.4$ $\mathrm{dB}$. Thus, the average increase in mean path gain via fivesite selection diversity for these frequencies is at least $15 \mathrm{~dB}$. Thus, site selection diversity both increases the mean path gain, and reduces the path gain variation. Worth noting is that the five-site-selected $G_{\max }$ typically-but not always-also yielded reductions in the path gain standard deviation (in $\mathrm{dB}$ ); for brevity we omit reporting on this statistic. We subsequently address improvements versus the number of sites used in selection.

In Fig. 6 we show cumulative distribution functions (cdfs) of path gain for each site for the $4860 \mathrm{MHz}$ frequency, with the rightmost curve for the maximum gain over all five sites. These cdfs are another way to quantify the site diversity gains. For this frequency, the minimum increase in path gain at the $30^{t h}$ percentile is $19 \mathrm{~dB}$, and the maximum increase in path gain is $33 \mathrm{~dB}$; for the $50^{t h}$ percentile (median path gain), the minimum increase of path gain is $13.7 \mathrm{~dB}$ and the maximum increase is $27 \mathrm{~dB}$. An alternative way of interpreting Fig. 6 is that for a given path gain, the probability of being below that gain is substantially reduced by use of site diversity. For example, for a minimum allowable path gain of $-110 \mathrm{~dB}$, the probability that the gain is less than or equal to $-110 \mathrm{~dB}$ ranges from 0.6-0.8 among the five individual sites, whereas for the five-site maximum, the probability that the path gain is less than or equal to $-110 \mathrm{~dB}$ is only 0.25 .

\section{B. Modeling Path Gains}

Large-scale fading (often termed "shadowing") is commonly modeled as being lognormal in distribution, or Gaussian in decibel units. This pertains to the power variation at a specific link distance. For our received power samples, which contain both LOS and NLOS samples, distance varies. We are aware of no widespread model for the power distribution in these conditions. Thus, we attempted to fit the received power samples to several distributions; in the end, the lognormal yielded the best fit. (All fits were done with a "distribution fitting tool" built in to our analysis software, which applies 


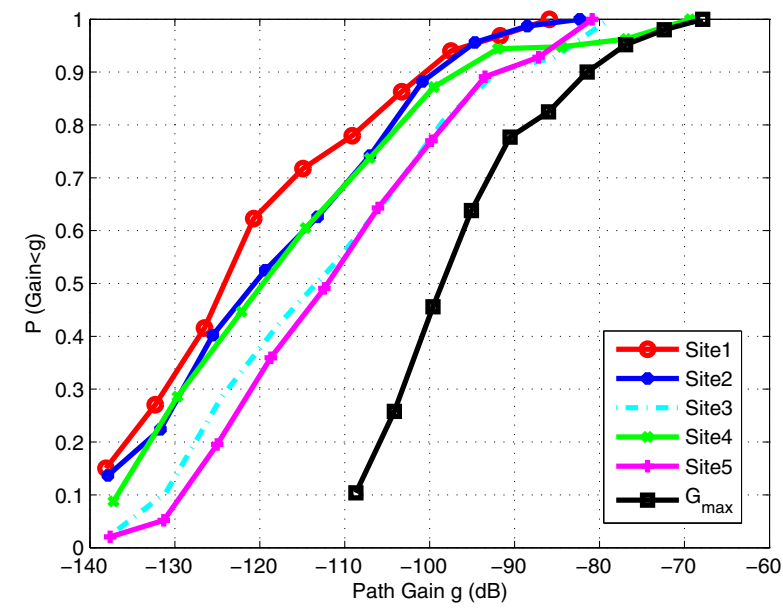

Fig. 6. Received power cumulative distribution functions for all five sites, and for five-site-maximum, $4860 \mathrm{MHz}$.

the maximum-likelihood algorithm.)

The Gaussian fit was the best approximation among several common candidate distributions (Rayleigh, Weibull, Gamma) [44]. Thus, we proceeded with our analysis assuming the lognormal distribution for path gain at each site, for each frequency.

We computed correlation coefficients for received path gains among all pairs of sites at each frequency to study the expected correlations between received signal powers at multiple sites (e.g., when both sites have a clear LOS). We found that coefficients typically ranged from -0.1 to 0.1 , with occasional larger values for isolated site pairs at specific frequencies. Thus, the path gains are nearly uncorrelated. Because uncorrelated Gaussians are independent, we conduct our analysis under the assumption that path gains at all sites are independent. This assumption will make the improvements from our diversity analysis optimistic, but it greatly simplifies analysis. Including correlation among the power levels requires numerical evaluation [45] for the joint distribution when the inter-site correlations are not all identical, as they are in our realistic case. The uncorrelated approximation we use simplifies the analysis, and is corroborated by simulations.

We briefly describe the method to compute the cdf of $G_{\max }$. The probability density function (pdf) of a lognormal random variable $y$ is [44]

$$
f_{Y}(y ; \mu, \sigma)=\frac{1}{y \sigma \sqrt{2 \pi}} \exp \left\{-[\ln (y)-\mu]^{2} /\left(2 \sigma^{2}\right)\right\},
$$

which applies for $y>0$, and $\mu$ and $\sigma$ are the mean and standard deviation of the variable $y^{\prime}$ s natural logarithm, respectively. The cdf for this lognormal is given by

$$
F_{Y}(t ; \mu, \sigma)=\frac{1}{2} \operatorname{erfc}\left[\frac{-(\ln (t)-\mu)}{\sigma \sqrt{2}}\right]=\Phi\left(\frac{\ln (t)-\mu}{\sigma}\right),
$$

where $\operatorname{erfc}$ is the complementary error function, and $\Phi$ is the standard normal cdf. Then, given the mean and standard deviation values (in natural log scale) computed from each single site's path gain data, (2) allows us to plot the analytical cdf for each site individually. The cdf of $G_{\max }$, generalized for a total of $L$ sites, is [43]

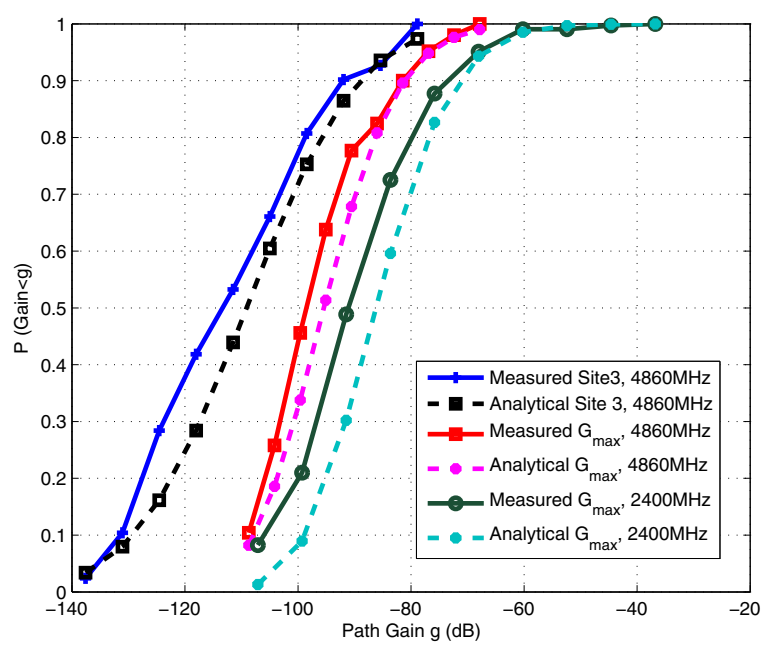

Fig. 7. Measured and analytical cdfs for received power for a single site (site 3) at $4860 \mathrm{MHz}$, and for the maximum over five sites for both 4860 and $2400 \mathrm{MHz}$.

$F_{P_{\max }}(z)=P\left(G_{\max } \leq z\right)=P\left(G_{1} \leq z, G_{2} \leq z, \cdots, G_{L} \leq z\right)$.

With the assumption of independence, the probability in (3) becomes a product of the $L$ individual probabilities; i.e., a product of the $L$ individual cdfs:

$$
F_{G_{\max }}(z ; \vec{\mu}, \vec{\sigma})=\prod_{k=1}^{L} F_{Y_{k}}\left(z ; \mu_{k}, \sigma_{k}\right),
$$

where $\vec{\mu}$ and $\vec{\sigma}$ are the vectors of means and standard deviations for each of the $L$ sites. (Recall that each site has a different mean and standard deviation).

Although the standard deviation of the path gain represents physical variations in the channel, an additional source of uncertainty in the path gain estimate arises from measurement uncertainty. In [46], an extensive analysis of uncertainty for this measurement set-up was carried out. Sources of uncertainty in the transmitters and receiver were quantified and are summarized in Table III. The RSS-combined uncertainty is less than $2.8 \mathrm{~dB}$ over all frequency bands. Fig. 7 shows a measured and analytical cdf for site 3 (an example site) for $4860 \mathrm{MHz}$, and cdfs for $G_{\max }$ for both the 4860 and 2400 $\mathrm{MHz}$ bands. The inexactness of the lognormal approximation to the received gain distributions is the reason for the discrepancy between analysis and measurements. Nonetheless, the analytical cdfs are reasonable approximations to the measured cdfs, and could be used to assess maximum potential site diversity improvements. This analysis can also be used for an arbitrary number of sites via selection of $L$ in (4). Finally, for site diversity, we show a plot in Fig. 8 for increases in mean path gain as a function of the number of sites used in the selection. In this figure, the circles denote means of the maximum path gain plot, where the maximum is selected over the path gains for a subset of $k$ selected sites, with $k$ ranging from one to five. For each value of $k$, there are $C_{k}^{5}=5 ! /[k !(5-k) !]$ possible subsets of $k$ distinct sites, among which the maximum can be selected. Thus, for example, when 
TABLE III

CONTRIBUTIONS TO MEASUREMENT UNCERTAINTY.

\begin{tabular}{|c|c|c|c|c|}
\hline Name & Type & Uncertainty Description & Method of Estimate & Values (dB) \\
\hline$\overline{U_{\text {analyzer }}}$ & Type A & $\begin{array}{l}\text { Accuracy in spectrum analyzer } \\
\text { measurements. }\end{array}$ & Specified by the manufacturer. & $\begin{array}{c}<0.6 \\
\text { Typical }\end{array}$ \\
\hline$U_{\text {receiver }}$ & Type A & $\begin{array}{l}\text { Data collection system tests, including } \\
\text { laptop and spectrum analyzer. }\end{array}$ & $\begin{array}{l}\text { Collected statistical data for a known source over } \\
\text { a one day period, in an outdoor environment. }\end{array}$ & $\begin{array}{c}0.1 \\
(1.0 \text { for } 1834 \mathrm{MHz})\end{array}$ \\
\hline$U_{T R P}$ & Type A & $\begin{array}{l}\text { Transmitter reverberation chamber total } \\
\text { radiated power (TRP) measurements. }\end{array}$ & $\begin{array}{c}\text { Standard deviation of } 10 \text { independent } \\
\text { calculations of TRP. }\end{array}$ & 0.6 to 2.25 \\
\hline$U_{d r i f t}$ & Type B & Cable changes due to temperature. & Observations from previous uncertainty experiments. & $<0.2$ \\
\hline
\end{tabular}

TABLE IV

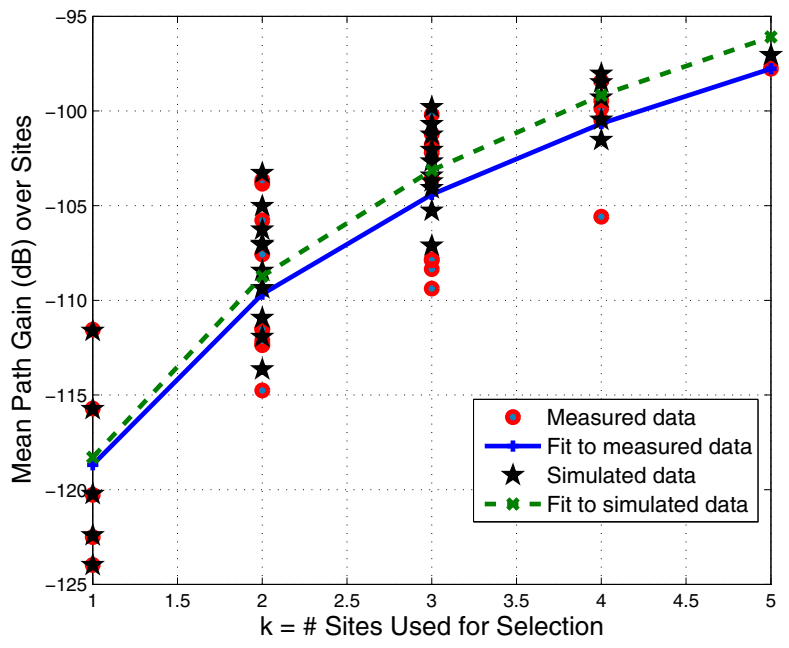

Fig. 8. Measured and simulated means of $G_{\max }$ when $k$-site selection is applied, for $4860 \mathrm{MHz}$.

$k=2$, we have $C_{2}^{5}=10$ possible sets of two sites for selecting the maximum. For each resulting $G_{\max }$ data plot collected over the $k$ power plots, the circles denote the mean of $G_{\max }$. The stars are mean values of $G_{\max }$ over $k$ sites obtained via a computer simulation, in which we draw lognormal random variables, with means and standard deviations equal to those of our measurements. As with the measured data, we select $k$ sites at a time, generate simulated received power samples for each of the $k$ sites according to the assumed lognormal distributions, select the maximum over the $k$ data plots, and then compute the mean gain of this maximum plot.

The two lines on Fig. 8 are least-squares fits to the data, both measured and simulated. The fits are of the form

$$
\bar{G}_{\max }(k)=c_{1} 20 \log _{10}(k)+c_{2},
$$

where $\bar{G}_{\max }(k)$ denotes the mean of the maximum path gain selected over $k$ sites, and $c_{1}$ and $c_{2}$ are fitting coefficients. For the measured data, $c_{1}=1.5, c_{2}=-88.7$, and for the simulated data, $c_{1}=1.59$ and $c_{2}=-88.3$. The simulated results show approximately the same trend and shape as the measured results as a function of the number of sites, and again lend credence to the lognormal received power distribution approximation. Results for the other frequencies show the same general trends, with slight changes to the coefficients. We can deduce from (6) that, in going from site
MINIMUM AND MAXIMUM REDUCTION IN PATH GAIN VARIATION VIA SIX-FREQUENCY SELECTION DIVERSITY (DB).

\begin{tabular}{|c|c|c|}
\hline Site & Minimum Variation Reduction & Maximum Variation Reduction \\
\hline 1 & 2 & 12 \\
\hline 2 & 6 & 17 \\
\hline 3 & 14 & 26 \\
\hline 4 & 5 & 21 \\
\hline 5 & 10 & 24 \\
\hline
\end{tabular}

diversity using $k-1$ sites to $k$ sites, we gain approximately

$$
G_{s}(k)=30 \log _{10}[k /(k-1)] d B .
$$

\section{FREQUENCY DIVERSITY}

Our received power measurements at the six frequencies were made sequentially over several hours. Thus, the pedestrian and vehicular traffic within the area varied somewhat. Nonetheless, by our averaging over small-scale fading (spatially, just as we did for site diversity), we can assume that the dominant large-scale fading effects (path loss and obstruction by buildings) were constant over the entire measurement period; any variation of shadowing by vehicles such as buses or trucks should be moderate and affect only a small portion of each frequency's data. Hence, we can analyze gains by frequency diversity at each site using methods analogous to those we described for site diversity. Tables IV and V show the same statistics as in the site diversity case. Path gain plots for a given site, for all six frequencies, look very similar to the site diversity path gain plots in Fig. 5. The path gain cdfs also appear similar. The improved channel characteristics for frequency diversity, both in measurement and for the analytic case, can be attributed to the frequency dependence of the environment (losses and reflectivity are a function of frequency). Fig. 9 shows example cdfs for site 3 , analogous to Fig. 7. As in the site diversity case, we also show analytical results obtained by use of the lognormal assumption. Conclusions similar to those for site diversity apply analogously for frequency diversity.

We also computed the increases in mean path gain, analogous to Fig. 9, and least-squares fits of the format of (5), where in $\bar{G}_{\max }(k)$, now $m \in\{1,2, \cdots, 6\}$ denotes the number of distinct frequencies instead of distinct sites. The fitting coefficients for this case, for site 3 , are $c_{1}=1.74, c_{2}=-79.8$ for the measured data, and for the simulated data, $c_{1}=1.81$ and $c_{2}=-78$. 


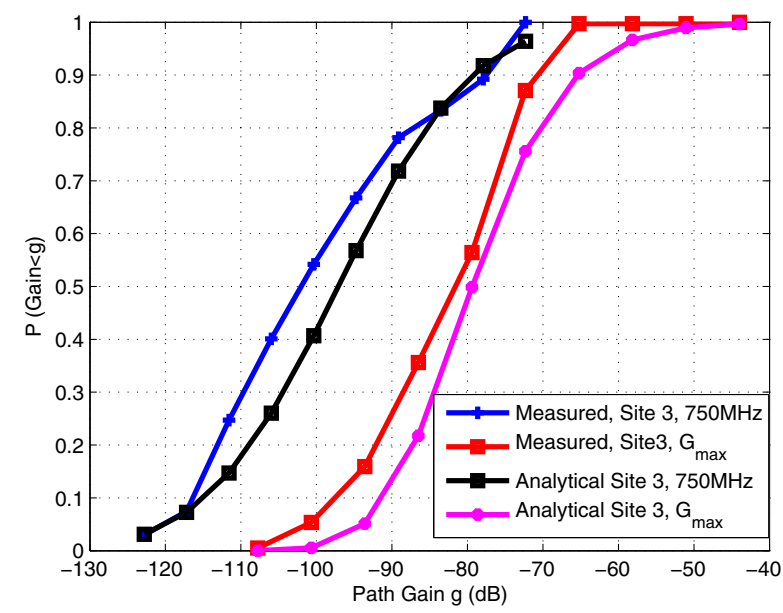

Fig. 9. Measured and analytical cdfs for received power for a single frequency $(750 \mathrm{MHz})$ and the maximum over six frequencies for site 3 .

TABLE V

STATISTICS FOR INCREASES IN MEAN PATH GAIN (DB, OVER ALL SIX FREQUENCIES) VIA SIX-FREQUENCY SELECTION DIVERSITY.

\begin{tabular}{|c|c|c|c|}
\hline Site & $\Gamma_{\min }$ & $\Gamma_{\text {avg }}$ & $\Gamma_{\max }$ \\
\hline 1 & 9.5 & 18.5 & 21.7 \\
\hline 2 & 19 & 23.3 & 30.5 \\
\hline 3 & 21 & 25.9 & 29.1 \\
\hline 4 & 17 & 21 & 27.1 \\
\hline 5 & 20.7 & 24.5 & 33.7 \\
\hline
\end{tabular}

\section{Combined Site And Frequency Diversity}

In the interest of brevity, we comment only briefly on the combined effects of frequency and site diversity. Via the independent lognormal assumption for path gains at all frequencies and all sites, we can select the maximum path gain among the Cartesian product of the set of sites $\{k\}_{k=1}^{5}$ and the set of frequencies $\{m\}_{m=1}^{6}$. This set, in our case, has $5 \times 6=30$ elements. As with frequency or site diversity alone, the combined case shows that the analytical cdfs are again optimistic, but that the general shape of the measured curves follows that of the analytical. Tables VI and VII summarize the improvements in channel characteristics when $L=30$ elements are combined.

\section{CONCLUSION}

In this paper, we provided results from measurements of received signal power, converted to path gain, at five simultaneous sites in an urban environment, for six distinct frequencies in or near public-safety frequency bands, for peerto-peer conditions. Results for site and frequency selection diversity show that substantial increases in mean path gain can be obtained. Mean path gain increases of at least $15 \mathrm{~dB}$ were found for selection over five sites (over all six frequencies). In addition, the range of path gain variation is reduced by site selection, by up to $17 \mathrm{~dB}$ to $29 \mathrm{~dB}$, depending on frequency. Similar increases were observed via frequency diversity.

By modeling the path gain as lognormal in distribution, we provided an analytical method for computing the cumulative distribution function of path gain, either per-site, per-
TABLE VI

MINIMUM AND MAXIMUM REDUCTION IN PATH GAIN VARIATION VIA SIX-FREQUENCY AND FIVE-SITE SELECTION DIVERSITY (DB).

\begin{tabular}{|c|c|c|}
\hline $\begin{array}{c}\text { Site \& } \\
\text { Frequency }\end{array}$ & $\begin{array}{c}\text { Minimum } \\
\text { Variation Reduction }\end{array}$ & $\begin{array}{c}\text { Maximum } \\
\text { Variation Reduction }\end{array}$ \\
\hline All & 19 & 45 \\
\hline
\end{tabular}

TABLE VII

STATISTICS FOR INCREASES IN MEAN PATH GAIN (DB, OVER ALL FIVE SITES AND SIX FREQUENCIES) VIA SELECTION DIVERSITY.

\begin{tabular}{|c|c|c|c|}
\hline Site \& Frequency & $\Gamma_{\min }$ & $\Gamma_{a v g}$ & $\Gamma_{\max }$ \\
\hline All & 28.8 & 38.1 & 50.1 \\
\hline
\end{tabular}

frequency, or for the maximum over a number of sites or frequencies (or both). The analytical results show reasonable agreement with measurements, and generally provide an upper limit to the expected improvements via selection. Simulation results were also used to corroborate the increases in mean path gain via selection of the maximum, and we provided an empirical relation for estimating mean path gain increases over $k$ sites, $m$ frequencies, or both.

Our analysis indicated that improvements in coverage may be realized in a dense urban area by use of location and/or frequency diversity. Future work may involve additional processing and curve-fitting for development of additional relationships that may be useful to ad hoc network designers in this type of urban environment.

\section{ACKNOWLEDGMENT}

For their assistance in measurements, the authors thank Galen Koepke, Jason Coder, and Dennis Camell of NIST. We thank William F. Young of NIST for developing the uncertainty analysis for the measurement system. This work was funded by the NIST Public Safety Communications Research Laboratory within the NIST Office of Law Enforcement Standards, Dereck Orr, Program Manager.

\section{REFERENCES}

[1] T. L. Doumi, "Spectrum considerations for public safety in the United States," IEEE Commun. Mag., vol. 44, no. 1, pp. 30-37, Jan. 2006.

[2] K. Balachandran, K. C. Budka, T. P. Chu, T. L. Doumi, and J. H. Kang, "Mobile responder communication networks for public safety," IEEE Commun. Mag., vol. 44, no. 1, pp. 56-64, Jan. 2006.

[3] TIA, "TIA-902.BAAB-A Wideband Air Interface Scalable Adaptive Modulation (SAM) Physical Layer Specification: Public Safety Wideband Data Standards Project: Digital Radio Technical Standards," Sept. 2003, www.tiaonline.org.

[4] IEEE 802 standards web site, http://standards.ieee.org/getieee802/portfolio.html, Sept. 2010.

[5] Third Generation Partnership Project, 3GPP, web site, www.3gpp.org, Sept. 2010.

[6] F. Li, Y. Wang, "Routing in vehicular ad hoc networks: a survey," IEEE Veh. Technol. Mag., vol. 2, no. 2, pp. 12-22, June 2007.

[7] P. Gupta and P. R. Kumar, "The capacity of wireless networks," IEEE Trans. Inf. Theory, vol. 46, pp. 388-404, Mar. 2000.

[8] F. Xue and P. R. Kumar, "The number of neighbors needed for connectivity of wireless networks," Wireless Netw. (ACM Journal), vol. 10, no. 2, pp. 169-181, Mar. 2004.

[9] C. Comaniciu and H. V. Poor, "On energy-efficient cross-layer design: joint power control and routing for ad hoc networks," EURASIP J. Wireless Commun. \& Netw., Article ID 60706, vol. 2007.

[10] M. Van der Schaar and S. Shankar, "Cross-layer wireless multimedia transmission: challenges, principles, and new paradigms," IEEE Wireless Commun. Mag., vol. 12, no. 4, pp. 50-58, Aug. 2005. 
[11] K. Stamatiou and J. G. Proakis, "Assessing the impact of physical layer techniques on ad hoc network performance," Physical Commun. J. (Elsevier), vol. 1, pp. 84-91, 2008.

[12] G. Ferrari, S. A. Malvassori, and O. K. Tonguz, "On physical layeroriented routing with power control in ad hoc wireless networks," in Proc. 2008 IET Communications, vol. 2, no. 2, pp. 306-319.

[13] A. Otyakmaz, R. Schoenen, S. Dreier, and B. H. Walke, "Parallel operation of half- and full-duplex FDD in future multi-hop mobile radio networks," in Proc. 2008 European Wireless Conf., pp. 22-25.

[14] P. W. C. Chan, et al., "The evolution path of 4G networks: FDD or TDD?" IEEE Commun. Mag., vol. 44, no. 12, pp. 42-50, Dec. 2006.

[15] Q. Zhang and D. W. Matolak, "Analysis of relay network duplexing, multiplexing, \& multiple access: application to aeronautical networks," in Proc. 2010 IEEE Aerospace Conf., pp. 6-13.

[16] D. W. Matolak, "Duplexing, multiplexing, and multiple access: a comparative analysis for mesh networks," in Proc. 2008 MILCOM, pp. 17-19.

[17] O. K. Tonguz and G. Ferrari, Ad Hoc Wireless Networks: A Communication Theoretic Perspective. John Wiley \& Sons, 2006.

[18] C. S. R. Murthy and B. S. Manoj, Ad Hoc Wireless Networks: Architectures and Protocols. Prentice-Hall, 2004.

[19] G. Aggelou, Mobile Ad Hoc Networks: From Wireless LANs to $4 G$ Networks. McGraw Hill, 2005.

[20] A. Schmitz and M. Wenig, "The effect of the radio wave propagation model in ad hoc networks," in Proc. 2006 ACM Int. Workshop on Modeling, Analysis \& Simulation of Wireless Mobile Systems.

[21] H. Rutagemwa, T. J. Willink, and L. Li, "Modeling and performance analysis of cooperative wireless networks," IEEE Trans. Veh. Technol., vol. 59, no. 6, pp. 3057-3069, July 2010.

[22] H. Sethu and T. Gerety, "A new distributed topology control algorithm for wireless environments with non-uniform path loss and multipath propagation," Ad Hoc Networks (Elsevier), vol. 8, pp. 280-294, 2010.

[23] B. K. Lau, M. A. Jensen, J. Medbo, and J. Furuskog, "Single and multiuser cooperative MIMO in a measured urban microcell environment," IEEE Trans. Antennas Propag., vol. 60, no. 2, pp. 624-632, Feb. 2012.

[24] J. D. Parsons, The Mobile Radio Propagation Channel, 2nd ed. John Wiley \& Sons, 2000.

[25] A. F. Molisch, Wireless Communications. John Wiley \& Sons, 2005.

[26] E. S. Sousa, V. M. Jovanovic, and C. Daigneault, "Delay spread measurements for the digital cellular channel in Toronto," IEEE Trans. Veh. Technol., vol. 43, no. 4, pp. 837-847, Nov. 1994.

[27] G. Calcev, et al., "A wideband spatial channel model for system-wide simulations," IEEE Trans. Veh. Technol., vol. 56, no. 2, pp. 389-403, Mar. 2007.

[28] A. A. M. Saleh and R. A. Valenzuela, "A statistical model for indoor multipath propagation," IEEE J. Sel. Areas Commun., vol. SAC-5, no. 2, pp. 128-137, Feb. 1987.

[29] D. W. Matolak, "Channel modeling for vehicle-to-vehicle communications," IEEE Commun. Mag., vol. 46, no. 5, pp. 76-83, May 2008.

[30] J. R. Hampton, N. M. Merheb, W. L. Lain, D. E. Paunil, R. M. Shuford, and W. T. Kasch, "Urban propagation measurements for ground based communication in the military UHF band," IEEE Trans. Antennas Propag., vol. 54, no. 2, pp. 644-654, Feb. 2006.

[31] D. W. Matolak, K. A. Remley, C. L. Holloway, C. Gentile, Q. Wu, and Q. Zhang, "Peer-to-peer urban channel characteristics for two public safety frequency bands," to appear in IEEE Antennas Propag. Mag., 2014.

[32] M. Riback, J. Medbo, J.-E. Berg, F. Harryson, and H. Asplund, "Carrier frequency effects on path loss," IEEE 2006 VTC - Spring.

[33] C. Oestges, N. Czink, B. Bandemer, P. Castiglione, F. Kaltenberger, and A. J. Paulraj, "Experimental characterization and modeling of outdoorto-indoor and indoor-to-indoor distributed channels," IEEE Trans. Veh. Technol., vol. 59, no. 5, pp. 2253-2265, June 2010.

[34] P. E. Mogensen. P. Eggers, C. Jensen, and J. B. Andersen, "Urban area radio propagation measurements at 955 and $1845 \mathrm{MHz}$ for small and micro cells," in Proc. 1991 Globecom.

[35] B. Van Laethem, F. Quitin, F. Bellens, C. Oestges, and P. De Doncker, "Correlation for multi-frequency propagation in urban environments," Progress In Electromagnetics Research Lett., vol. 29, pp. 151-156, 2012.

[36] C. L. Holloway, G. Koepke, D. Camell, K. A. Remley, S. A. Schima, M. McKinley, and R. T. Johnk, "Propagation and detection of radio signals before, during, and after the implosion of a large convention center," NIST Technical Note 1542, June 2006.

[37] C. L. Holloway, W. F. Young, G. Koepke, K. A. Remley, D. Camell, and Y. Becquet,"Attenuation of radio wave signals coupled into twelve large building structures," NIST Technical Note 1545, Feb. 2008.

[38] K. A. Remley, G. Koepke, C. L. Holloway, C. Grosvenor, D. Camell, J. Ladbury, D. Novotny, W. F. Young, G. Hough, M. D. McKinley, Y. Becquet, and J. Korsnes, "Measurements to support broadband modulatedsignal transmissions for the public-safety sector," NIST Technical Note 1546, Apr. 2008.
[39] W. F. Young, C. L. Holloway, G. Koepke, D. Camell, Y. Becquet, and K. A. Remley, "Radio wave signal propagation into large building structures-part I: CW signal attenuation and variability," IEEE Trans. Antennas. Propag., pp. 1279-1289, Apr. 2010.

[40] K. A. Remley, G. Koepke, C. L. Holloway, C. Grosvenor, D. Camell, J. Ladbury, R. T. Johnk, and W. F. Young, "Radio wave signal propagation into large building structures-part 2: characterization of multipath," IEEE Trans. Antennas. Propag., pp. 1290-1301, Apr. 2010.

[41] Berkeley Varitronics Systems, Inc., website www.bvsystems.com, Sept. 2010.

[42] W. C. Jakes, Ed., Microwave Mobile Communications. IEEE Press, 1994.

[43] G. L. Stuber, Principles of Mobile Communication, 2nd ed. Kluwer Academic Publishers, 2001.

[44] A. Papoulis and U. Pillai, Probability, Random Variables, and Stochastic Processes, 4th ed. McGraw-Hill, 2001.

[45] J. Zhang and V. Aalo, "Effect of macrodiversity on average error probabilities in a Ricean fading channel with correlated lognormal shadowing," IEEE Trans. Commun., vol. 49, no. 1, pp. 14-18, Jan. 2001.

[46] W. F. Young, K. A. Remley, G. Koepke, D. Camell, and J. Healy, "Performance analysis of RF-based electronic safety equipment in a subway station and the Empire State Building," NIST Technical Note 1792, Mar. 2013.

David W. Matolak $\left(\mathrm{S}^{\prime} 82, \mathrm{M}^{\prime} 83, \mathrm{SM}^{\prime} 00\right)$ is a professor in the Department of Electrical Engineering at the University of South Carolina, where he has been since 2012. He was also a faculty member at Ohio University from 1999-2012. He has approximately 20 years of experience with various types of communication systems, including work with private industry (AT\&T Bell Labs, L3 Communications, Lockheed Martin Telecom.) and federal government organizations (Rural Electrification Administration, MITRE). Dr. Matolak received the B.S. degree from The Pennsylvania State University in 1983, the M.S. degree from The University of Massachusetts in 1987, and the Ph.D. degree from The University of Virginia in 1995, all in electrical engineering. His areas of expertise and current interest are statistically nonstationary wireless channel measurement and modeling, ad hoc networking, multicarrier wireless transmission, and aeronautical communications. He has conducted sponsored research for NASA, the NSF, the Air Force/DARPA, NIST, and the FAA. He has also consulted for several industries, and has been a visiting professor at NIST Boulder Labs, the University of Malaga, Spain, and NASA Glenn Research Center. Dr. Matolak is a member of Eta Kappa $\mathrm{Nu}$, Sigma Xi, and a Senior Member of IEEE. He has published several book chapters, more than 80 refereed articles, more than 50 technical reports and other conference papers, more than 45 industry technical reports, and has 8 patents. He is also an Editor for the IEEE TRANSACTIONS ON VEHICULAR TECHNOLOGY, and the International Journal of Intelligent Transportation Systems Research.

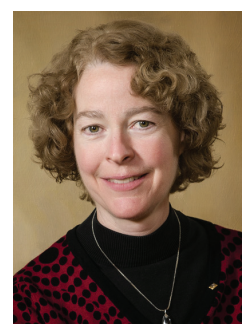

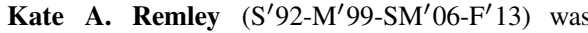
born in Ann Arbor, MI. She received the Ph.D. degree in Electrical and Computer Engineering from Oregon State University, Corvallis, in 1999.

From 1983 to 1992 , she was a Broadcast Engineer in Eugene, OR, serving as Chief Engineer of an AM/FM broadcast station from 1989-1991. In 1999, she joined the Electromagnetics Division of the National Institute of Standards and Technology (NIST), Boulder, CO, as an Electronics Engineer. She is currently the leader of the Metrology for Wireless Systems Project at NIST, where her research activities include development of calibrated measurements for microwave and millimeterwave wireless systems, characterizing the link between nonlinear circuits and system performance, and developing standardized test methods for RF equipment used by the public-safety community.

Dr. Remley was the recipient of the Department of Commerce Bronze and Silver Medals, an ARFTG Best Paper Award, and is a member of the Oregon State University Academy of Distinguished Engineers. She was the Chair of the MTT-11 Technical Committee on Microwave Measurements from 20082010 and the Editor-in-Chief of IEEE Microwave Magazine from 2009-2011. 


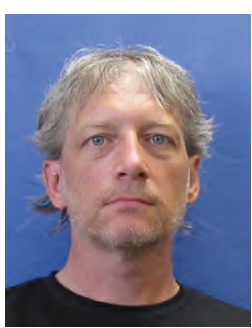

Christopher L. Holloway (S'86-M'922-SM'04F'10) is a Fellow of the IEEE and received thee B.S. degree from the University of Tennessee at Chattanooga, and thee M.S. and Ph.D. degrees from the University of Colorado at Boulder, both in electrical engineering. During 1992 he was a Research Scientist with Electro Magnetic Applications, Inc. in Lakewood, Co. From the fall of 1992 to 1994 he was with the National Center for Atmospheric Research (NCAR) in Boulder, Co. While at NCAR his duties included wave propagation modeling, signal processing studies, and radar systems design. From 1944 to 2000 he was with the Institute for Telecommunication Sciences (ITS) at the U.S. Department of Commerce in Boulder, Co., where he was involved in wave propagation studies. Since 2000 he has been with the National Institute of Standards and Technology (NIST), Boulder, CO, where he works on electromagnetic theory. He is also on the Graduate Faculty at the University of Colorado at Boulder. Dr. Holloway received the 2013 IEEEE APS Society Edward E. Altshuler Award, 2008 IEEE EMC Society Richard R. Stodart Award, the 2006 Department of Commerce Bronze Medal for his work on radio wave propagation, the 1999 Department of Commerce Silver Medal for his work in electromagnetic theory, and the 1998 Department of Commerce Bronze Medal for his work on printed circuit boards. Dr. Holloway is currently serving as chair for US Commission A of the International Union of Radio Science and is an Associate Editor for the IEEE TRANS ACTIONS ON ELECTROMAGNETIC COMPATIBILITY. Dr. Holloway's research interests include electromagnetic field theory, wave propagation, guided wave structures, remote sensing, numerical methods, metamaterials, measurement techniques, EMC/EMI issues, and atom based metrology.

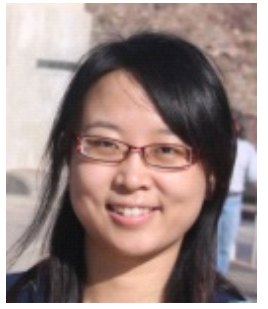

Qian Zhang received the M.S. degree and the Ph.D. degree both from Ohio University, U.S. in 2008 and 2012, respectively, in electrical engineering. Her M.S. thesis topic was wireless near-ground channel characterization in several unlicensed bands. During her masters degree, she interned at Alcatel-Lucent Inc. in summer 2007. Her Ph.D. dissertation topic was comparing duplexing, multiplexing and multiple access techniques in ad hoc networks. During her $\mathrm{Ph} . \mathrm{D}$. degree, she worked as a research intern at the National Institute of Standards and Technology (NIST) in 2009 and was awarded a NIST grant for the 2009-2010 academic year. She was also awarded an Ohio University named graduate fellowship from 2011 to 2012 for innovative research. She has interned at InterDigital Inc. in 2011 and worked on the project of cellular networks with deviceto-device communications. In 2012, Dr. Zhang joined InterDigital Inc. as a senior engineer. She is currently working on the small cell milimeter wave backhaul mesh networks. Her areas of expertise and current interest are wireless channel measurement and modeling, ad hoc networking, device-todevice communications and millimeter wave mesh networking.

Qiong Wu Photo and biography not available at the time of publication. 